\title{
Reverend Alex Dyer: Tradition and Innovation in the Episcopal Church
}

Interviewed by Ashley Makar

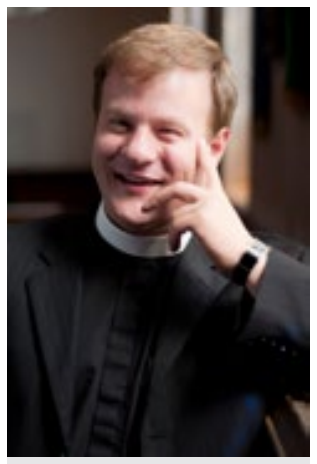

Rev. Alex Dyer

Ashley Makar interviewed Reverend Alex Dyer, priest-in-charge of St. Paul and St. James Episcopal Church of New Haven, CT in May 2011.

Ashley Makar: What is your religious background?

Alex Dyer: I'm a Christian in the Episcopal Tradition.

Ashley Makar: And you were raised in the Episcopal tradition?

Alex Dyer: I was not, actually. I was unchurched at age 15 and I found the church that way.

Ashley Makar: Perhaps you might discuss any encounters you've had with images and objects in your religious practice?

Alex Dyer: When I was growing up, not too much. I just kind of avoided that, I didn't know the basic Bible study stories. There was no crosses or nothing really until I started going to church, and then basic kind of stuff. We'd go on retreats and get the nice, little, wonderful Hallmark Jesus stuff. I think I started getting into icons probably in college. Took a trip to Jerusalem and discovered those and since then iconography has shaped my worship and my faith.

Ashley Makar: How has it shaped your worship?

Alex Dyer: Well, I love different kinds of icons. There's a traditional kind but then there's Coptic and everything else too. [I like] discovering the way certain people write icons, how they view things and the colors or what not [they choose]. I find it helpful sometimes to be focused on a certain event or something like that. To have that there or to have a certain image of Christ realizing that that's not an idol, but just a window to 
help me worship.

Ashley Makar: And you find that more in your personal devotional worship or in your role as a minister?

Alex Dyer: Well, both. I've used it both in private and corporate worship. I have a whole bunch handy hanging on my wall in my office, and in every office [at every church] I've served. I have a few around the house as well. It's as outward, visible reminders of why I'm in this gig.

Ashley Makar: Has that been challenging in congregational settings? Have you found people that are uncomfortable with icons or...?

Alex Dyer: Not in my particular tradition. Maybe 10 or 20 years ago it might have been jarring but they're a little more popular today. It's usually just something that's a conversational piece. You know: "they're beautiful," and, "tell me about it" or something like that. I've never had any negative reactions to them.

Ashley Makar: This might be along the same lines, but discuss any images or objects that you consider of religious significance in your worship spaces and in your home.

Alex Dyer: Again the icons-but there are also crosses, and I've got a few reproductions of paintings hanging in my office as well. I also have some more "interesting" pieces, a collection. I guess you could define them as art: bobblehead Jesus and glow-in-the dark Jesus. To relate to the lighter side.

Ashley Makar: You have them in your office?

Alex Dyer: Yes. And probably more eyebrows are raised for that, but a part of that is representing a lighter side of things. I do believe that God's got a sense of humor.

Ashley Makar: Yes, I certainly hope so.

Alex Dyer: As far as the worship space, I've probably had the chance to explore that more at my present congregation [than anywhere else]-with fabric, and we put up icons around the worship space from time to time.

Ashley Makar: And do you keep the Stations [of the Cross] hanging or is that just during Lent?

Alex Dyer: No that's just during Lent, but it was amazing how many comments I got on that. People were coming in, very struck by that. I think it's good to use art or fabric or whatever to give a change in the worship space. In fact, when I got here they were very attentive about that. [They said,] "We want to notice that liturgical seasons are changing." The congregation came to me and said, "This is what we want." There's some intentionality for each season. It has given me an opportunity to exercise a little bit of 


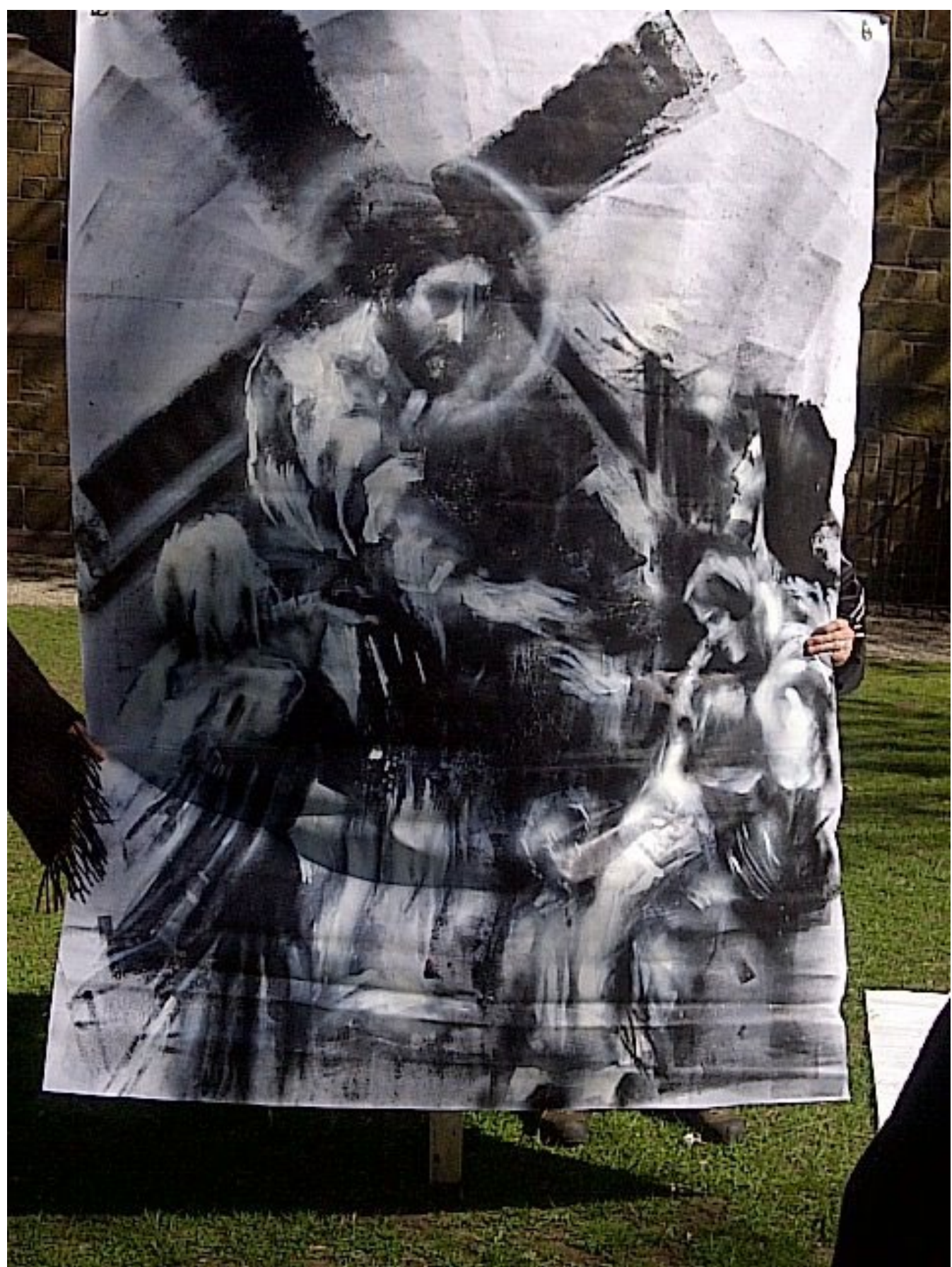

One of a series of paintings of the Stations of the Cross made by Katro Storm for St. Paul and St. James

creativity.

Ashley Makar: And how have you done that, indicated the seasons?

Alex Dyer: Well, the Stations will be one example. Art, but also everything from the candlesticks to the type of fabric we hang. Advent and Lent are more barren times and Easter's more richness. 
Ashley Makar: Right. What do you do with the fabric?

Alex Dyer: Well, we've draped it across the entrance to our columbarium. Right now it's white drapes on the side of the top of the columbarium. In a sense it's a shroud, like Jesus leaving the tomb.

Ashley Makar: Is it white?

Alex Dyer: It's white, yes. So, it would be white for this season and then it'll be green; we'll do a red for Pentecost.

Ashley Makar: In the lives of an individual or a community engaged in religious practice, which images or objects do you think are most prevalent and meaningful?

Alex Dyer: In my tradition, because we're so sacramental, the font and altar are very important. In most of my congregations, there's been a kind of a reredos behind the altar. ${ }^{1}$

Ashley Makar: A what? What's that?

Alex Dyer: At St. Paul and St. James it's the wooden thing with the icons of Jesus. Not actually icons, but [images of saints and angels with one large central image of Jesus.] It depicts different things [at different churches] and the stone altar usually has some [imagery] in itself. At Trinity there was a marble [altar]; there were two angels and what not. It's kind of a focal point. Eucharistic. Not that we're worshiping the altar; that's just a focal point for what happens there.

Ashley Makar: Yes. It's to orient the whole liturgical movement.

Alex Dyer: Yes. Everything springs forth from the font and the altar.

Ashley Makar: Where's the font in relation to the altar?

Alex Dyer: At St. Paul and St. James? The font is right in the entrance. Right when you walk in, connected to the columbarium; they connect birth and Baptism together. It's intrinsic to the church, too. We have the privilege of having a baptistery. The font itself, they're usually decorated. Those are kind of the core images to us. I mean, of course, there's stuff like crosses that hang around, and we have a wonderful chapel with an [altarpiece of the nativity] in the back, and there's an icon over the altar. Maybe people find that lovely and centering to their worship. But yes, mainly font and altar for us.

Ashley Makar: What role does physical space, environment, or nature play in your religious practice?

Alex Dyer: Well, Episcopalians love their buildings, there's no doubt about that. We take 


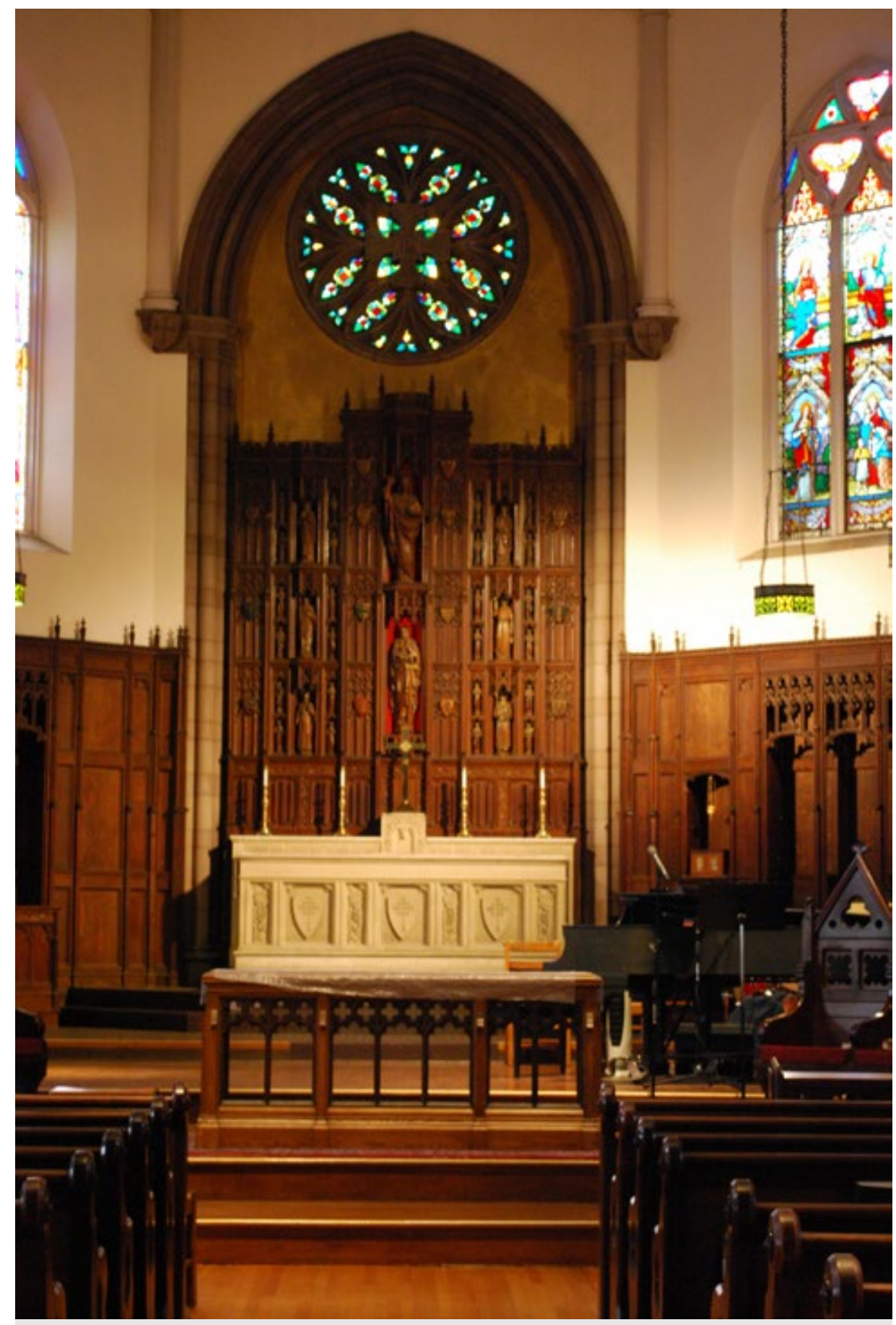

View of the reredos at St. Paul and St. James

great pride in our buildings as worship space. We set a sense of the holiness: that it is something different that you're walking into. Physical space is important to us. If you want to find that out, just try messing with stuff. Try moving some furniture around and you'll see just how important it is. I think it's crucial to who we are as Episcopalians.

Ashley Makar: How do you negotiate that with the Chapel on the Green?² Since you don't have the building. 


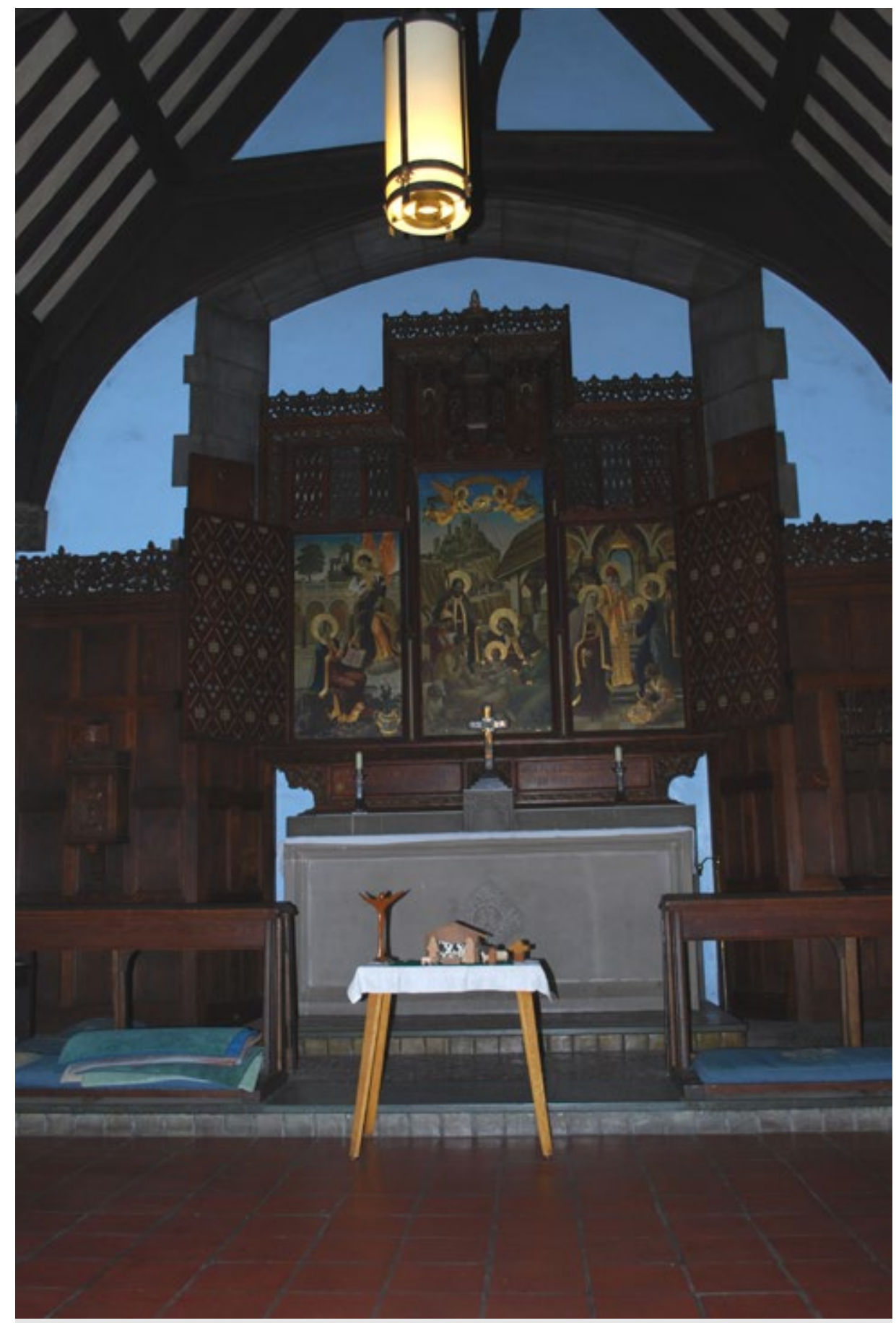

Chapel of the Nativity, Church of St. Paul and St. James

Alex Dyer: It's funny, even with Chapel on the Green, you still get a comment if you move the altar or something like that. I mean, granted, since it's not a fixed altar there's a bit more leeway, but if you put it underneath the tree as opposed to behind the church or something like that, once in a while people will comment. I noticed after a month or two [of doing the service] we kind of figured out some ideal spots. You still create physical space there. In a sense we've created some physical boundaries. I've intentionally tried to mix that up more with Chapel on the Green: "Hey, we've been doing it this way so let's 
mess things around a little bit so that we don't get too solidified." I think it's important that it has some consistency, but it's a different animal.

Ashley Makar: Yes. It definitely feels like a distinct space. Even though there's not a circle it feels like a circle.

Alex Dyer: Yes. But the lack of pews or kneelers or anything else like that allows people [to approach the service differently]. Physical space is always different in Chapel on the Green. You've got the people who are very much a part of the service. They've got bulletins in their hands, they're closer to the altar, and they're very much participating. There's an inner circle, and then there's another outlying area where people are engaged and you walk around and give communion and you know they're ready for it, but if you were walking by, you might think, "Oh they're not a part of this service." And then you've got people who-

Ashley Makar: People on the periphery?

Alex Dyer: Yes. On the periphery, people can be on the park bench who are gleaning something from this as well too.

Ashley Makar: You don't approach the people [for communion] if they're sitting on the benches do you?

Alex Dyer: Usually not, usually not. I mean, some ambitious priests do: "Body of Christ?" But generally we stick to people standing or sitting in the immediate area. But yes, the physical space is always there, and it's affected how I view inside the church too; how to get people up, how restricting physical space can be sometimes.

Ashley Makar: It seems that at Chapel on the Green it depends a lot on movement. Movement creates the space as much as does physical stationary objects.

Alex Dyer: Yes. I do think we have to have some kind of space, so we frame it cognitively. We like to say, “This is ___."You know, it's kind of funny. Some people will come up to me and complain about people smoking on the edges and say, "This is church!" As one person said, "You shouldn't smoke in church!" And I'm like, "It's also kind of the Green. And they're showing up." It's just so funny. Some people have their preconceived notions of what happens inside the church and-I'm trying to be pastoral to their responses but inside thinking: "Wow." I'm shaking my head, "Huh, interesting."

Ashley Makar: Have there been any teachings in your religious community about images, objects and sensory experience with religious practice?

Alex Dyer: Not in my current one. In the first church I started at there was a gentlemen who was very interested iconography who taught a class for the parish. And at Trinity, ${ }^{3}$ we walked through with the youth group one time and said, "This is why churches are designed this way," etc. 
Ashley Makar: Yes, well the stained glass at Trinity-

Alex Dyer: It's gorgeous. I talked through that. And, "This is the altar. It looks like the inside of a ship." And all that other stuff that goes along with the physical building.

Ashley Makar: I think you've covered this, but what is the role of images or objects in your religious practice?

Alex Dyer: They're pretty important. We are sensory worship, you know? Sight, sound, very tactile, I think. And then the sense of the Sacraments.

Ashley Makar: What sorts of arts education have you had in your professional training, in your theological education, or in your education at large?

Alex Dyer: Most of it has been on-job training. There were classes offered and some other stuff at the seminary, but I honestly didn't think it was that important.

Ashley Makar: You went to GTS [The General Theological Seminary of the Episcopal Church]?

Alex Dyer: Yes, and they were offered as electives and I got some basic stuff in the Liturgy classes, but it's an ongoing thing, and it varies from congregation to congregation. The congregation of St. Paul and St. James where I am right now is very interested in art, they're more artistic people.

Ashley Makar: And have images or objects played a role in your training?

Alex Dyer: Well yes, like I said, we're very tactile. I think priests like to have their toys. So as far as objects, I would say definitely.

Ashley Makar: And liturgical training?

Alex Dyer: Yes, liturgical training, the vestments. They're works of art. So I mean, just having to navigate the space and... Yes.

Ashley Makar: In leading services do you consider what you wear as being an aesthetic choice?

Alex Dyer: Yes, definitely an aesthetic choice: chasubles depict imagery, a lot of times just symbols. They are very important. Do you wear just a stole, do you wear a chasuble, do you wear a coat, all that stuff plays in the setting, and can really set the mood of the service. We play with that a lot at St. Paul and St. James, having what some people might classify as non-traditional music. We do some non-traditional things, yet being very traditional in what we wear and what we do and some other things. It's the juxtaposition of those two. It's been fun to play with. 
Ashley Makar: What kind of effects do you think that's had on the congregation?

Alex Dyer: I think people like it because a lot of people think that you can't have both, that if you're going to do a "Jazz Eucharist," you have to be...

Ashley Makar: More casual.

Alex Dyer: Much more casual, and I've always, even since the seminary, I always liked saying you can do both with integrity. I guess some people call it "blended worship." I think the congregation has appreciated it. A lot of people have been able to frame worship differently. They were concerned about being traditional, but they can still hold on to some of the creatures of comfort [and] be willing to go to new places. And those people who maybe don't value the heritage or the tradition as much can see that it can be done in new ways.

Ashley Makar: Right. They can appreciate the tradition in a different context.

Alex Dyer: Exactly.

Ashley Makar: In what ways do you address space and movement in worship?

Alex Dyer: In our best services, we move around, we process in a liturgical party. When we baptize we go back to the font. We all gather around the font. We've played with it. I think back recently to Holy Week. Our Maundy Thursday service was at tables around the altar or in the church space, and then, as a part of the service, we had a cleaning of the tables and putting the tables away.

Ashley Makar: Was that already a liturgy that had been written or did you create it?

Alex Dyer: We borrowed it from churches around. They used to do it in the Parish home but then I said, "Let's eat in the church." They really liked it. Good Friday we stripped the church down bare. We did the stripping of the altar on Maundy Thursday. We processed an icon up of the crucifixion, and we placed it on the altar. In the service we had people go and place flowers on it.

Ashley Makar: That's beautiful. What kind of flowers did they bring?

Alex Dyer: Tulips. And then those tulips were reused. They do a flowering of the cross: they have a cross that's got little holes in it that you can put flowers in so you get a cross of flowers. So, the same flowers that were used to lay were then reused.

Ashley Makar: When did you do the flowering?

Alex Dyer: Easter morning. They were laid at the grave of Jesus and everything. Resurrection. So we've played with objects and images a lot and they're hungry for more 
of that. We got a Calvin worship grant to explore some more ways we can incorporate art.

Ashley Makar: A what grant?

Alex Dyer: Calvin worship grant. ${ }^{4}$ A renewal worship grant. To look and to talk with the congregation [about] how we can incorporate more art and imagery.

Ashley Makar: And what kinds of things are you thinking about?

Alex Dyer: I'd love for us to be more open to moving towards having art in the worship space. That would be lovely to see. For years religion has produced some wonderful art, or artists have produced wonderful art based on religion.

Ashley Makar: And are you thinking both religious art and secular art with religious things?

Alex Dyer: Possibly, yes. With certain congregations that would not do well; I think this congregation would be fine with that. I've encouraged my director of music to say, "Let's not say something is secular." I mean, let's be honest, there are certain songs you shouldn't play in church.

Ashley Makar: Right.

Alex Dyer: But there are certain songs that one might say are secular but have a very spiritual meaning and a deeper meaning to people. So I said, "Everything's on the table, like let's talk about everything." So, we played, "People Get Ready" which was a popular song in the 70's, you know, and played on the radio. We played a John Mayer song once in church. So, let's not say that anything's off the table. One person might come in and say that this is secular. I've heard it said that in God there is no secular or sacred. God is all sacred. That's the ethos of this church.

Ashley Makar: How do you understand the arts to be resources for your leadership?

Alex Dyer: Art twitches us to places that we wouldn't necessarily go. It sparks creativity into new places. We're pushed to new places. Art is very subjective. It challenges us to recognize that what $I$ may not like somebody else might find very deeply moving. It creates a little more diversity and acceptance.

Ashley Makar: Among the congregation?

Alex Dyer: Yes. I mean, there are some people who, for instance, really liked the Stations of the Cross, they just thought it's great. Some people were like, "Eh. It was all right." Nobody really had any super negative opinion about them, but there were some people who were just like, "Yeah, whatever, it is, it is. It's not great." But there were some people that were just moved by that and I think the people who were indifferent, they 


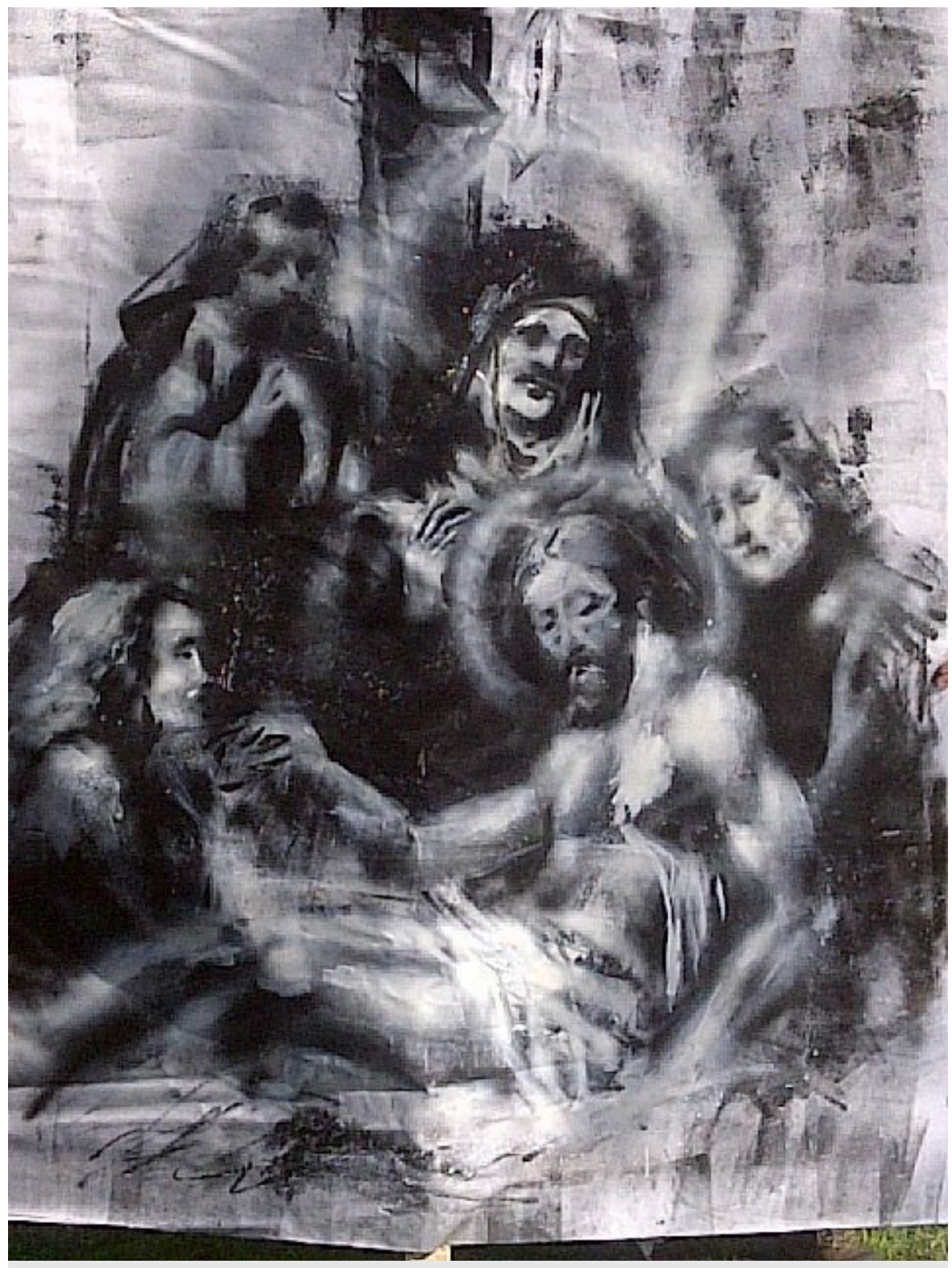

Katro Storm, Stations of the Cross

were almost a little curious to find out, "So what is it that [appealed so much to others]?" It sparked conversation.

Ashley Makar: And did you offer any guidance for people who weren't familiar with it?

Alex Dyer: Yes. It was written in our bulletin the first couple of weeks. We said, "This is the artist and this is the Stations of the Cross and what it depicts what not, and that it's on billboard material."

Ashley Makar: Is that a local artist?

Alex Dyer: It is. It is. Katro Storm. Very talented guy. Good guy. 
Ashley Makar: Yes. Those are beautiful.

Alex Dyer: He's done some other stuff too. It's just amazing.

Ashley Makar: Other stuff for church?

Alex Dyer: Just around, just other stuff. He'd did one on jazz musicians at one time too. He had a great experience doing it. I mean, he said it was very ... I don't know if he was religious or not before, but he'd never done anything like this and he didn't come from a tradition that really values Stations of the Cross. He did seven one year and then seven the next year, but the first year he did it ... it was actually ... I heard that he was held up a gun point. He was [working in his studio] in Bridgeport and, coming out one night, he got held up at gun point and he basically said, "Hey, I'm doing these pictures of Jesus ... I've got to finish this," and the guy let him go.

Ashley Makar: Wow. That's amazing.

Alex Dyer: He said he had quite a spiritual experience just doing it.

Ashley Makar: How do images, objects, and the arts or sensory experience relate to your leadership?

Alex Dyer: Since we value all these so much, I think it's something I've got to pay attention to as a leader. Every little nuance-how are things placed, what is the intention of placing the icon where you do or changing the liturgical colors, or all the art, is crucial to me as a leader to [determining] what mood you're trying to evoke from a congregation.

Ashley Makar: Can you talk a little about your congregant's interactions with the images, objects, and arts?

Alex Dyer: I think they draw a lot from that. Episcopalians more than other Christian traditions are very visual, very tactile, and this church is no exemption to that. They value all that. It brings them to a different place. You can see that when everything is stripped away during Good Friday or even when part of it is stripped away for Lent, people respond to that. Part of the joy of the resurrection is also a joy of completeness, having some of these things back to help and assist us in worship.

Ashley Makar: And do they ask you questions about it when you strip the stuff away?

Alex Dyer: Some people do. A lot of people are familiar with it. As our congregation grows, I think there will be more and more of that. Right now, we're almost all Episcopalians, familiar with the routine. There have still been comments in the sense of ... well, they hadn't had Stations of the Cross before so some of the former Roman Catholics knew what that was about and some were more like, "So tell me about this." 
Ashley Makar: Do you have anything you want to add to this conversation?

Alex Dyer: Not so much in the worship space, but what has really enhanced our congregation, and has probably, even though it's not in our worship space, affected our worship, is that mural downstairs: ${ }^{5}$ having the non-traditional saints and having some people who they recognize from the congregation in there. I think it's really got people to see things a little bit differently.

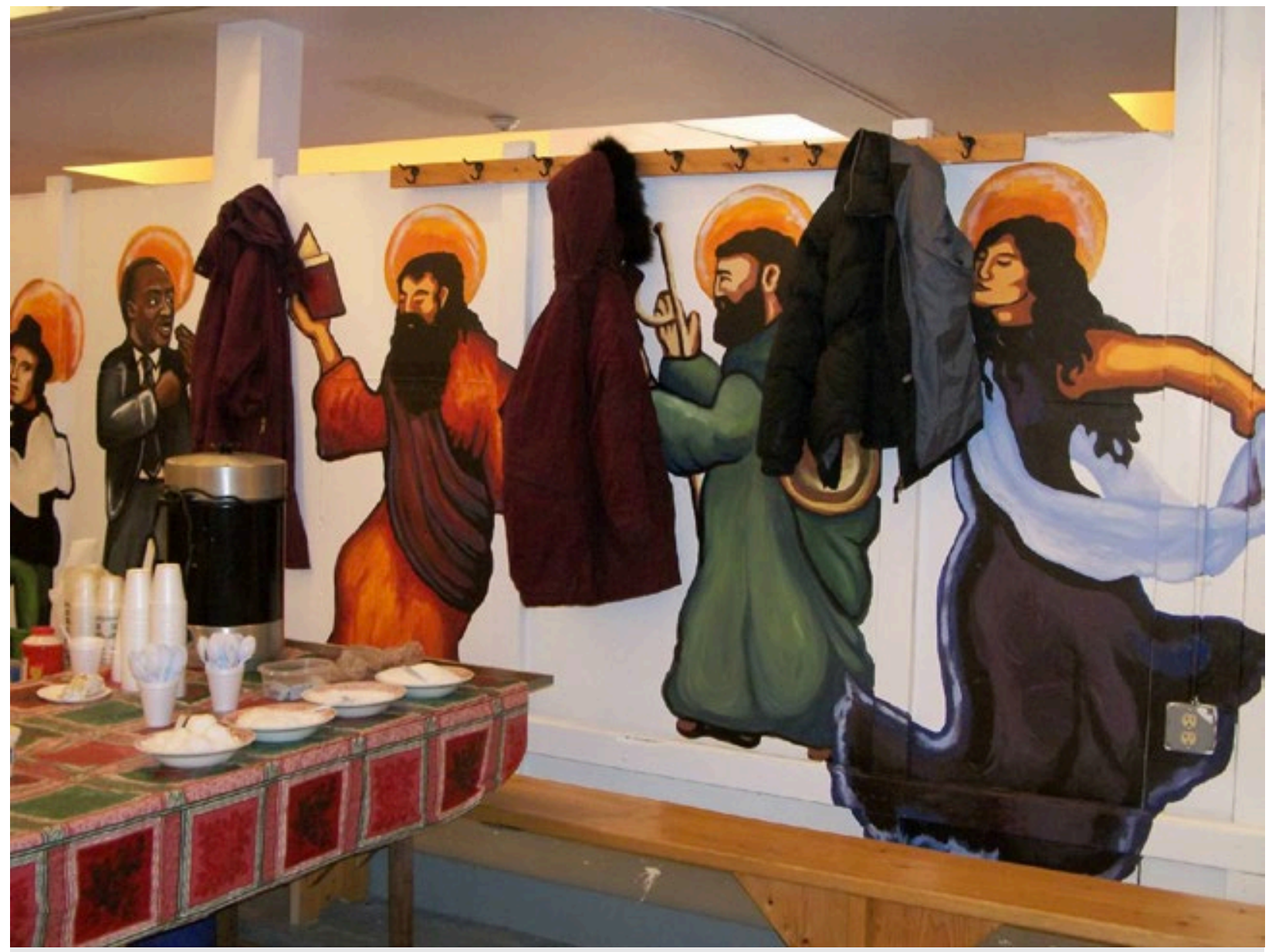

Julie Dickerson, Dance with the Saints Mural at St. Paul and St. James Church, New Haven, CT, 2010

Ashley Makar: How so?

Alex Dyer: I think they see it as more worshipful. That space used to just be the undercroft, now it's more sacred. And they're proud about it, a lot of people to the extent where [they'll say], "Oh, come down and see this mural," if people are visiting the church for the first time.

Ashley Makar: Their proud of it, it's part of their space.

Alex Dyer: And it tells their story, in a sense of who the saints are. It tells the story of this 
place.

Ashley Makar: And some of the saints were chosen by them?

Alex Dyer: Yes. Some of them were chosen by them or suggested by them. It's got St. Paul, St. James, it's got a lot of people from New Haven, it's got the New Haven ballet people. So, they can kind of tell their story through these images. That's fun to watch, and to see people coming and get a tour.

Ashley Makar: Do you think it has increased their interest in what happens in that space?

Alex Dyer: I think so. Yes. Before, it was painted in the Brazilian flag colors and so it looked very much like a capoeira studio, a Brazilian dance studio. ${ }^{6}$ Now it tells their story. It still fits in with everything else that goes on there too with the capoeira dancer and the flamenco dancer and the founder of AA there. Al Schumacher. So it's everybody's now. It's both ours and everybody's. It's transformed the mindset of the room, how we envision it, and how we view our own selves too, our sense of mission to the city and why we're here. It's transformed that space and it's transformed us in some ways. It's continuing to bear fruit.

Ashley Makar: Do you think there's also been an effect on the people who used the space for NA [Narcotics Anonymous] and AA meetings, to feel more a part of the church or

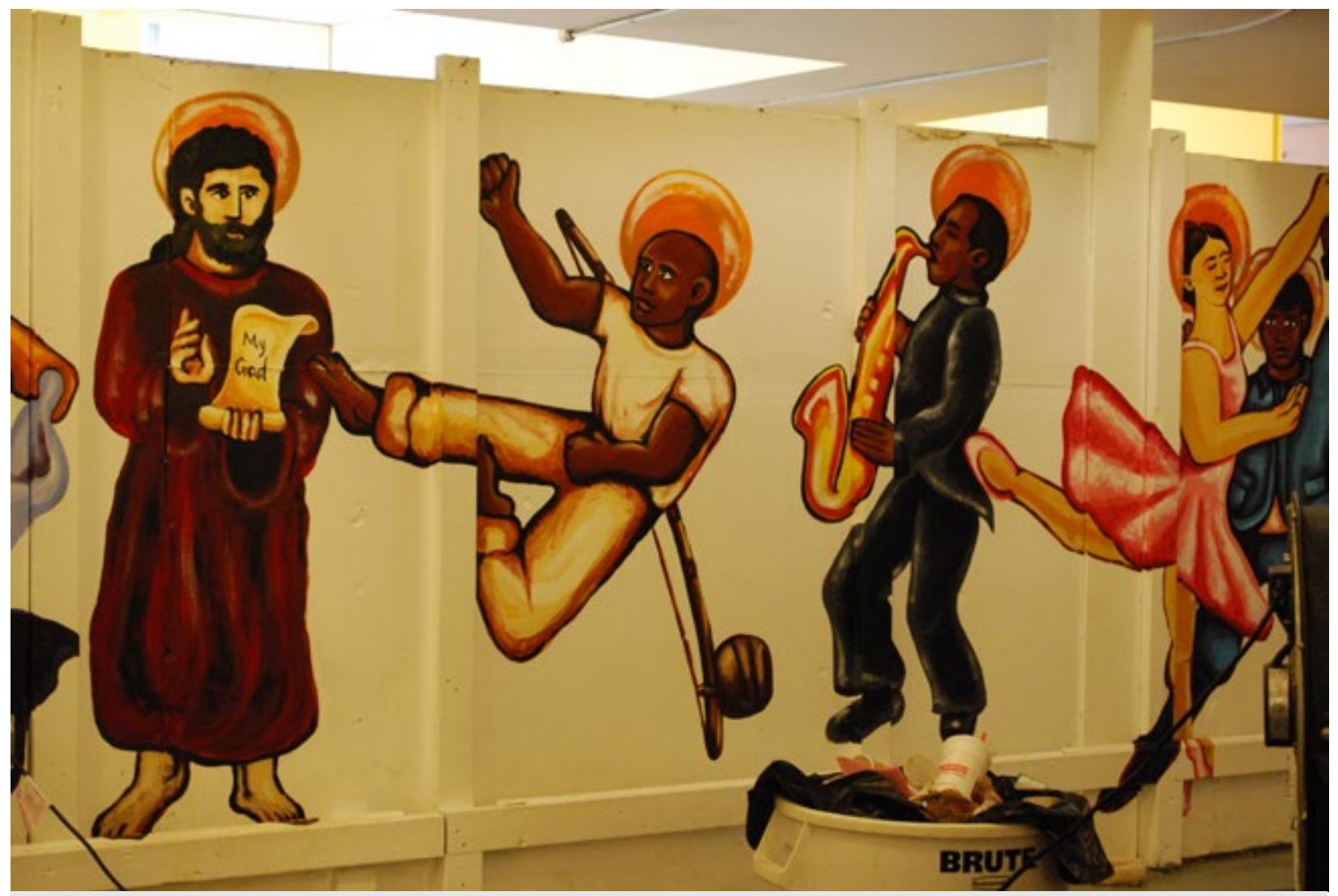

Detail of the Dance with the Saints mural, showing the capoeira dancer 
engaged in the church?

Alex Dyer: Yes. It tells our story and these are the people that are engaging into it too. Whether you're an Episcopalian or even a Christian, there's a sense of more that you're in church and this is more a sacred space.

Ashley Makar: Thank you.

(C) Ashley Makar

\section{Citation Guide}

1. "Reverend Alex Dyer: Tradition and Innovation in the Episcopal Church," by Ashley Makar, Interview, in Conversations: An Online Journal of the Center for the Study of Material and Visual Cultures of Religion (2015), doi:10.22332/con.int.2015.1

"Reverend Alex Dyer: Tradition and Innovation in the Episcopal Church." By Ashley Makar. Interview. In Conversations: An Online Journal of the Center for the Study of Material and Visual Cultures of Religion (2015). doi:10.22332/con.int.2015.1

\section{Notes}

1. A reredos is an alternate term for an altar screen, an ornamental screen or partition wall found behind the altar in a church. Altar screens may be made of wood or stone and often feature elaborate religious iconography.

2. Chapel on the Green, founded by Rev. Alex Dyer, takes place every Sunday at 2:00 pm on New Haven's Upper Green. The brief, outdoor service is open to the public and provides lunch afterwards to all who attend.

3. Rev. Dyer is referring to Trinity Episcopal Church on the Green, where he was affiliated prior to coming to St. Paul and St. James.

4. Rev. Dyer is referring to a grant from the Vital Worship Grants Program at the Calvin Institute of Christian Worship. See http://worship.calvin.edu/grants/

5. Rev. Dyer is referring to the Dance with the Saints mural painted in the church undercroft by Julie Dickerson. For more information about the mural, see Makar's interview with Dickerson, http://mavcor.yale.edu/conversations/interviews/juliedickerson-creative-currents

6. The church of St. Paul and St. James hosts a capoeira studio and AA meetings in the undercroft, among other things.

\section{Yale}

Copyright 2016 Yale University All rights reserved. 